\title{
Investigación y construcción del saber en la Nueva Escuela: el papel de la biblioteca escolar
}

\section{Kátia Corina Vieira}

Centro universitário Adventista de São Paulo (Brasil)

\subsection{Resumen}

Se analiza el papel de las bibliotecas escolares en la promoción de la investigación y el uso de las nuevas tecnologías en la escuela secundaria. La investigación se enmarca en el paradigma brasileño de renovación pedagógica conocido como "nueva escuela" o "escuela contemporánea", inspirado en el pensamiento de Paulo Freire y Dermeval Saviani, entre otros autores. Profesores, bibliotecarios - vistos como educadores - y alumnos deben formar una tríada que garantice la formación de los futuros investigadores, formando así individuos autónomos, críticos y capaces de cambiar la realidad intelectual del país.

Palabras clave: Educación secundaria. Formación para la investigación. Bibliotecas escolares. Renovación pedagógica.

\subsection{Abstract}

The role of school libraries in the promotion of research and new technologies in the secondary education is analysed. The discussion is framed from the Brazilian progressive educational paradigm named "new school" or "contemporary school", inspired in authors like Paulo Freire and Dermeval Saviani. Teachers, librarians - seen as educators - and students, should form a triad that guarantees the formation of the future researchers, forming autonomous and critical individuals, capable of changing the intellectual reality of the country.

Keywords: Secondary education. Research training. School libraries. Pedagogical reform.

\section{Introducción}

La investigación y su relación la construcción del saber en los años iniciales son los objetos de estudio de este artículo, en el que se reflexiona sobre como se está trabajando la relación entre investigación y adquisición del saber dentro del paradigma de la Nueva Escuela. En este artículo se presentan las propuestas iniciales de una investigación que está en curso. La idea de esta investigación surgió en uno de los encuentros semanales del grupo de estudio Paidea (Grupo de Estudios e investigación en Filosofía de la Educación de la Facultad de

Scire. 9 : 1 (en.-jun. 2003) 125-132. 
Educación de la Universidad de Campinas, São Paulo), coordinado por el profesor Dr. Silvio Gamboa.

La educación convencional en el Brasil asume que el contacto con la investigación propiamente dicha ha de ocurrir en la enseñanza superior. Este enfoque se ha demostrado improductivo desde el punto de vista académico, pues el alumno a esas alturas ya se ha deformado con conceptos como "investigar es copiar secciones de libros y al final colocar una conclusión". En su trayectoria escolar este tipo de trabajos resultaban aceptables, pero en la educación superior se le motiva a cuestionar, argumentar, escribir lo que piensa y lo que entiende sobre diversos asuntos. Pero esas son actividades que desconoce, porque prácticamente no tuvo oportunidad de practicarlas durante su trayectoria escolar.

La condición de subalternidad del alumno que esta situación nos muestra una realidad puede y debe ser modificada, ya que se basa en prácticas pedagógicas susceptibles de cambio. La búsqueda de un sujeto emancipado, autónomo, critico, apto para argumentar, que piense, que elabore y que tenga en la investigación una practica cotidiana, es el desafío del profesor-investigador. Entendemos por profesor investigador aquél que incorpora a su trabajo cotidiano la practica de la investigación, que escribe, publica e investiga. Pensamos que los profesores necesitan ser investigadores, toda vez que es difícil hablar y enseñar sobre lo que no se conoce efectivamente. Villardi ratifica esta idea cuando dice que: "El acto de enseñar presupone el conocimiento por parte de aquel que enseña; lo que transforma la investigación en una necesidad intrínseca a la enseñanza, sea cual sea el tipo de investigación a la que se dedique" (1999, p. 135). Por lo tanto, las proposiciones teórico-metodológicas que fundamentan la concepción de la investigación como practica educativa pueden cambiar la práctica real y cotidiana. En este reto, el profesor de enseñanza primaria resulta ser un aliado tanto en la busca de técnicas de enseñanza, como en la formación para la investigación y el uso de las tecnologías en el aula.

\section{2. ¿Cuál es la relación existente entre la investigación entre la investigación y el saber en la nueva escuela?}

Ahora bien, ¿por que estudiar el período de la Nueva Escuela? Porque se trata de un momento de transición en el que - a partir de reflexiones respaldas por autores y teorías que habían mostrado la necesidad de cambiar algunos hábitos aceptados sin crítica hasta ese momento - se incorporaron nuevas prácticas a la labor cotidiana del aula. En este movimiento, el saber, la investigación y la construcción del conocimiento fueron también foco de reflexiones y críticas que sirvieron para que sustentar un esfuerzo de concientización científica y metodológica. A partir de las conclusions de dichas reflexiones, consideramos necesario presentar proposiciones teórico-metodológicas que fundamenten la concepción de la inves-

Scire. $9: 1$ (en.-jun. 2003) 125-132. 
tigación en la practica educativa desde el primer año de la escuela primaria como una solución para el "problema" existente, que es un vacío que necesita ser llenado, porque la iniciación a la investigación se produce cuando el alumno entra a la universidad, y solo entonces va a tener contacto con monografías, artículos, etc., de investigación. Normalmente, todo el trabajo que debería haber sido realizado desde los primeros años de escolarización se lleva a cabo de una manera rápida en asignaturas como Metodología Científica o Técnicas de Investigación. En el conocimiento que el alumno trae consigo a la universidad no están las técnicas de investigación y de lectura. Normalmente no sabe hacer un trabajo sin copiar párrafos densos; y habitualmente no indica las fuentes, ni sabe parafrasear. Esto es así porque en el modelo tradicional de educación el profesor es el foco de conocimiento. Solo él sabe, solo a él le cabe la responsabilidad de saber.

Nuestra propuesta al respecto es reflexionar sobre las practicas pedagógicas de la nueva escuela a través de un análisis de la historia de la educación, especialmente en lo que concierne a esta transición. Para ello se propone una mudanza de hábitos mediante una metodología que permita trabajar con cuestiones epistemológicas e interdisciplinarias y que posibilite verificar la relación entre investigación y saber para la nueva escuela, teniendo como base a los Dermeval Saviani y Paulo Freire, aunteres ambos de renombre nacional y que participan del momento de transición de la escuela tradicional a la nueva escuela.

El cuestionamiento - y los procesos que genera de verificación de posibilidades y de argumentación - son actividades que están íntimamente ligadas a la educación y que tienen el objetivo de contribuir a la formación de un individuo con ideas propias, libre de dominación (sea política, social, etc.), y comprometido con la sociedad y con el avance de la ciencia. La investigación científica - tan discutida y relevante - puede y debe ser ensayada en los primeros años escolares de los alumnos. El cuestionamiento, la critica y la busca de los porqués deben ser incentivados desde la más tierna edad, haciendo así del educando un ser pensante, critico y consciente de la historia y la cultura de su país.

En general, el miedo o la timidez de profesores que no tienen el hábito de investigar desmotivan a los alumnos, apartándolos del gusto por esta práctica, cuyo inicio se desplaza al nivel superior. Pocos profesores, bien sea por incentivo particular o profesional, son investigadores. Por tanto, creemos que es oportuna una mayor reflexión sobre esta cuestión y cuanto de ella afecta a la vida del educando. El hecho de pretender trabajar la investigación en la fase primaria se justifica por la evidencia de que en la enseñanza de preparatoria se priorizan los contenidos que serán exigidos en los exámenes de admisión. Según Baccaglini (2000 p. 24): [...] esta visión utilitarista acaba por inhibir iniciativas que tengan por objetivo un conocimiento más cuidadoso y trabajar conceptos y fenómenos que exigen mas tiempo y reflexión para ser construidos, y que quizá por eso

Scire. $9: 1$ (en.-jun. 2003) 125-132. 


\section{Kátia Corina Vieira}

perjudicarían el desempeño de los alumnos en los exámenes de admisión”. Sin embargo en los años iniciales de enseñanza primaria esta cuestión se torna viable, ya que en cada disciplina existe la posibilidad de crear técnicas y momentos en los que la investigación científica ocurra de manera sutil, placentera, creativa e inteligente, despertando así la curiosidad y al mismo tiempo formando e incentivando mentes criticas. Sin embargo, esta idea no cala fácilmente en las mentes de muchos profesores y alumnos, cuando, en verdad, la investigación debería ser una practica cotidiana de todo profesor y alumno.

No solo la investigación es un instrumento de innovación del conocimiento, sino que el propio conocimiento es tan solo un medio, que, para ser educativo, necesita de la orientación de la ética de los fines y valores. En el sentido de ser a la vez práctica y teórica, la investigación incorpora la práctica que, al lado de la teoría, asume su marca política hasta el fin. Demo (1997, p. 7):

La marca política no aparece solo en la presencia inevitable de la ideología, sino sobre todo en el proceso de formación del sujeto critico y creativo, que encuentra en el conocimiento el arma más potente de innovación, para hacer y para crear oportunidades históricas a través de él. En este sentido, la ciudadanía que se forma en la escuela no puede ser una ciudadanía cualquiera. Más bien es específicamente aquélla que se sabe fundar en el conocimiento; primero, para educar en el conocimiento; y segundo, para establecer con competencia inequívoca una sociedad ética. Más equitativa y solidaria.

Sin embargo, normalmente el aula es apenas un lugar en el que el alumno recibe, en el que el conocimiento apenas es repasado y donde todo el proceso parece limitarse a un entrenamiento. No hay crecimiento, interacción ni participación. Demo (1977) va más allá y considera ese repaso mera copia, que "no educa más de lo que lo hace la conversación entre vecinos, o la conversación en una fiesta animada". Según Demo (1977) el cuestionamiento debe enmarcarse en la tentativa de reconstrucción del saber, no el mero cuestionar sin más horizonte; y entonces se hace esencial. Las ideas propias deben ser exploradas y expuestas por un sujeto critico que imprime su marca personal - su emancipación histórica - como signo permanente en el proceso. En mitad de esta reflexión, vale la pena volver a traer a colación - como contraste - la visión antigua que presentaba al alumno como alguien subalterno, que no pensaba y no debía ni se le permitía participar, que debía permanecer quieto, tan solo anotando, asimilando la enseñanza, haciendo las pruebas, y con la mera obligación, por todo horizonte, de pasar el año. Esta imagen retrógrada es prescindible. El alumno debe ser orientado y conducido. Viene a la escuela para trabajar con otros, buscando en el profesor un incentivador, un orientador. En palabras de Coll:

[...] ciertamente, el alumno es el responsable final del aprendizaje en la medida en que él construye su conocimiento, atribuyendo sentido y significado a los contenidos

Scire. $9: 1$ (en.-jun. 2003) 125-132. 
de la enseñanza; pero es el profesor el que determina con su actuación como es su enseñanza, las actividades en las cuales el alumno participa y que van a posibilitar un mayor o menor grado de amplitud y profundidad de los significados construidos; y, sobre todo, quien asume la responsabilidad de esta construcción en una determinada dirección. (1994, p. 156)

El aula clásica, tradicional - donde el alumno no participa, solo escucha, hace las tareas y pruebas - necesita ser evaluada. Es necesario denunciar la imagen del profesor autoritario dueño del conocimiento que muchas veces al sentirse amenazado por el alumno no deja espacio para que éste participe en las clases. Cabe aquí destacar la cuestión del trabajo en equipo, la motivación grupal. Ambos - profesor y alumno - necesitan estar formados para que este trabajo alcance los objetivos esperados. Trabajar en equipo o en pareja no es siempre fácil, pero el conjunto de habilidades que supone pueden aprenderse muy bien en el aula si el alumno encuentra en el profesor su aliado. El trabajo individual y colectivo no se excluyen, sino que son interdependientes y se enriquecen mutuamente.

Las enseñanza orientada al alumno como propone la nueva escuela - permitiendo el movimiento, la comunicación y la interacción, buscando diversas maneras de participación sin que para ello tenga que desaparecer el silencio-, debería ser el objetivo de los profesores, porque es necesario buscar el equilibrio colectivo y no sólo el individual. Se debe motiva e incentivar a nuestros niños para el trabajo solidario, en equipo, el saber argumentar, él buscar el porqué de todo y la interdisciplinariedad -indispensable para el trabajo en equipo-.

Por tanto, consideramos apropiado promover una cultura en la que los profesores defiendan la práctica de la investigación en el aula. El conocimiento empaquetado - que tan solo necesita ser desenvuelto para ser impartido- es normalmente el mas utilizado por una serie de razones entre las que se puede destacar su practicidad, objetividad, la falta de tiempo para la investigación, la falta de motivación, etc. Con todo, es necesaria la reflexión, pues la sociedad está cada vez mas necesitada de sujetos autónomos, emancipados, de ciudadanos comprometidos con la sociedad en la que están inmersos. La investigación tiene un papel fundamental en este aspecto, pues en la medida en que motivamos a buscar información y cuestionamos las recetas rápidas, fomentamos la iniciativa y contribuimos a la formación de agentes sociales activos y comprometidos.

Ahora bien, no se puede hablar de investigación, enseñanza, conocimiento y docencia, sin considerar la aportación de la biblioteca. Al final, la biblioteca resulta ser el ambiente más propicio para buscar la información en sus más variados soportes. Desgraciadamente, en muchas de nuestras escuelas no hay biblioteca, y el alumno acaba teniendo acceso a este ambiente solo cuando llega a la universidad. Con todo, la biblioteca no es una garantía absoluta para que se produzca 
el conocimiento, sino una herramienta intermedia entre el mundo de la palabra escrita y el discurso polémico, menos verbal y más basado en imágenes.

Saviani y Paulo Freire, autores brasileños y de renombre internacional, han criticado abiertamente a la escuela tradicional por limitarse a entregar paquetes listos a los alumnos, respuestas listas repasadas por el profesor, que se comporta como el dueño del saber. Al mismo tiempo, denuncian que no hay apoyo ni incentivo a las bibliotecas y que no existe preocupación por el uso de recursos que faciliten el aprendizaje y motiven a los alumnos a buscar por sí solos una mayor comprensión. Dicho en palabras de Saviani (1995, p. 547):

La enseñanza tradicional se centra en él profesor, en los contenidos y en su aspecto lógico - esto es, se centra en el profesor, el adulto que domina los contenidos lógicamente estructurados, organizados-; mientras que los métodos nuevos se centran en el alumno (los niños), en los procedimientos y en los aspectos psicológicos - esto es, se centran en las motivaciones e intereses de los niños, en desarrollar los procedimientos que les conduzcan a poseer los conocimientos capaces de responder a sus dudas e indagaciones - En suma, aquí, en los métodos nuevos, se privilegian los procesos de obtención de conocimientos, mientras que en los métodos tradicionales se privilegian los métodos de transmisión de los conocimientos ya obtenidos.

Por otro lado, ambos autores difieren en sus opiniones tratándose de enseñanza e investigación. Para Saviani, enseñanza es diferente de investigación. Según este autor, no los podemos confundir; pues la enseñanza trasmite saberes científicos privilegiados, clásicos, y en ella se obtiene información sobre fenómenos; mientras que en la investigación, el objeto de conocimiento tiene que estar presente. Por su parte, Paulo Freire acepta la relación polémica entre enseñanza e investigación, aunque los fenómenos no estén presentes, sino tan solo referidos a través de los discursos de los profesores, los alumnos y otros medios de comunicación como imágenes, bibliotecas, recursos gráficos, círculos culturales, etc. Para él, la investigación revela el mundo desvelado.

\section{Bibliografía}

Ayuste, Ana et al. (1998). Participación y no participación en educación de personas adultas en España: un enfoque comunicativo y crítico en investigación. // Educação \& Sociedade. Campinas, SP. 19:63 (Aug. 1998) 15.

Baccaglini, Carlos A. C. (2000). O professor, a construção do currículo e as tecnologias. // Revista da Educação. PUC-Campinas. 8 (jun.2000) 22-27.

Borges, Cecília. (2001). Saberes docente: diferentes tipologias e classificações de um campo de pesquisa. // Educação \& Sociedade. Campinas, SP. 22:74 (Apr. 2001). URL: $<$ http://www.scielo.br/scielo.php?script=sci_arttext\&pid>. Consultado:27/05/2002.

Boutinet, Jean-Pierre. (2002). Antropologia do projeto. Porto Alegre: Artmed, 2002.

Calazans, Julieta. (1999). Iniciação científica: construindo o pensamento crítico. São Paulo: Cortez, 1999.

Scire. $9: 1$ (en.-jun. 2003) 125-132. 
Campos, Maria Malta (1999). A formação de professores para crianças de 0 a 10 anos: modelos em debate. // Educação \& Sociedade. Campinas, SP. 20:68. (fev. 1999).

Coll, César (1994). Aprendizagem escolar e construção do conhecimento. Porto Alegre: Artes Médicas, 1994.

Demo, Pedro (2000). Educar pela pesquisa. Campinas, SP: Autores Associados, 2000.

Demo, Pedro (2000). Saber pensar. São Paulo: Cortez; Instituto Paulo Freire, 2000.

Demo, Pedro (1997).Pesquisa e construção de conhecimento. Rio de Janeiro: Tempo Brasileiro, 1997.

Demo, Pedro (1999). Pesquisa: princípio científico e educativo. São Paulo: Cortez, 1999.

Gamboa, Silvio Sánchez (1998). Fundamentos para la investigación educativa: presupuestos epistemológicos que orientan al investigador. Santa Fe de Bogotá: Cooperativa Editorial Magisterio, 1998.

Garcia, Rolando (2002). O conhecimento em construção: das formulações de Jean Piaget à teoria de sistemas complexos. Porto Alegre: Artmed, 2002.

Gauthier, Jacques (1999). O que é pesquisar: entre Deleuze-Guattari e o camdoblé, pensando mito, ciëncia, arte e culturas de resistência. // Educacão \& Sociedade. Campinas, SP. 20:69. (Dezembro 1999). URL: <http://www.scielo.br/scielo.php?script=sci_arttext.> Consultado: 27/05/2002.

Grinspun, Mirian P. S. Zippin (Org.) (1999). Educação Tecnológica: desafios e perspectivas. São Paulo: Cortez, 1999.

Fazenda, Ivani (1995). (Org.) A pesquisa em educação e as transformações do conhecimento. Campinas, SP : Papirus, 1995.

Freire, Paulo (1979). Considerações em torno do ato de estudar. // Freire, Paulo. Ação cultural para a liberdade e outros escritos. Rio de Janeiro: Paz e Terra. 1979. 9-12.

Freire, Paulo (1992). Pedagogia da esperança. Rio de Janeiro: Paz e Terra, 1992.

Freire, Paulo (1991). A escola na cidade. São Paulo: Cortez, 1991.

Freire, Paulo (1993). Nova Escola. São Paulo: Editora Abril Cultural, 1993.

Lacerda, Mitsi Pinheiro de (2002). Pesquisas de professoras de escolas. // Ensinar e aprender: sujeitos, saberes e pesquisa. Encontro Nacional de Didática e Prática de Ensino. Belo Horizonte: ENDIPE, 2002.

Lüdke, Menga (2000). A pesquisa e o professor da escola básica: que pesquisa, que professor?. // Ensinar e aprender: sujeitos, saberes e pesquisa. Encontro Nacional de Didática e Prática de Ensino. Rio de Janeiro: ENDIPE, 2000.

Lüdke, Menga (2001). O professor, seu saber e sua pesquisa. // Educação \& Sociedade. Campinas, SP. 22:74 (Abril 2001). URL: <http://www.scielo.br/scielo.php?=sci_ arttext\&pid>. Consultado: 27/05/2002.

Luna, Sérgio Vasconcelos de (2000). Planejamento de pesquisa. São Paulo: EDUC, 2000.

Mantoan, Maria Teresa Eglér (1999). Interatividade virtual e presencial na construção de conhecimentos de professores e alunos da escola fundamental: um estudo exploratório. // Revista de Educação. PUC-Campinas. 3:7 (novembro 1999) 52-57.

Marafon, Maria Rosa Cavalheiro (2001). Pedagogia crítica: uma metodologia na construção do conhecimento. Petrópolis, RJ: Vozes, 2001.

Scire. $9: 1$ (en.-jun. 2003) 125-132. 


\section{Kátia Corina Vieira}

Mello, Suely Amaral (2000). Linguagem, consciência e alienação: o óbvio como obstáculo ao desenvolvimento da consciência crítica. Marília, SP.: UNESP, 2000.

Nunes, Célia Maria Fernandes (2001). Saberes docentes e formação de professores: um breve panorama da pesquisa brasileira. // Educação \& Sociedade. Campinas, SP. 22: 74 (Abril 2001). URL: <http://www.scielo.br/scielo.php?script=sci-_arttext\&pid> Consultado: 27/05/2002.

Oliveira, Silvio Luiz de (1997). Tratado de metodologia científica. São Paulo: Pioneira, 1997.

Oliveira, Inês Barbosa de; Alves, Nilda (2002). Pesquisa no/do cotidiano das escolas: sobre redes de saberes. Rio de Janeiro: DP\&A, 2002.

Saviani, Dermeval (1983). Escola e democracia. São Paulo: Cortez; Autores associados, 1983.

Saviani, Dermeval (1991). Pedagogia histórico-crítica: primeiras aproximações. São Paulo: Cortez/Autores Associados, 1991.

Saviani, Dermeval (1987). Tendências e correntes da educação brasileira. // Mendes, D.T. (coord.). Filosofia da Educação Brasileira. Rio de Janeiro: Civilização Brasileira, 1987.

Sampaio, Marisa Narciso (1999). Alfabetização tecnológica do professor. Petrópolis, RJ: Vozes, 1999.

Severino, Antônio Joaquim; Fazenda, Ivani Catarina Arantes (Orgs.) (2001). Conhecimento, pesquisa e educação. Campinas, SP: Papirus, 2001.

Silva, Márcia Barbosa da (2000). Mídias na formação do educador e o processo de pesquisa. // Ensinar e aprender : sujeitos, saberes e pesquisa. Encontro Nacional de Didática e Prática de Ensino. Rio de Janeiro: ENDIPE; DP\&A: 2000.

Silva, Waldeck Carneiro da (1999). Miséria da biblioteca escolar. São Paulo: Cortez, 1999.

Ternes, José (2002). Bachelard: epistemologia e ensino. // Ensinar e aprender: sujeitos, saberes e pesquisa. Encontro Nacional de Didática e Prática de Ensino. Belo Horizonte: ENDIPE,2002.

Vieira, Sofia Lerche (2002). Pesquisa em sala de aula: aprender a pesquisar, pesquisando. // Ensinar e aprender : sujeitos, saberes e pesquisa. Encontro Nacional de Didática e Prática de Ensino. Belo Horizonte: ENDIPE, 2002.

Villardi, Raquel (1999). Iniciação científica na formação do professor: Trilhas em construção. // Iniciação Científica: construindo o pensamento crítico. São Paulo: Cortez, 1999. 129-140. 